\title{
Le concile de Trente et I'Inquisition romaine. À propos des procès en matière de foi au concile
}

\section{Alain Tallon}

\section{Résumé}

Alain Tallon, Le concile de Trente et I'Inquisition romaine. À propos des procès en matière de foi au concile, p. 129-159.

Le présent article traite des rapports difficiles et des conflits de juridiction entre le concile de Trente et l'Inquisition romaine, principalement lors de la troisième période du concile (1562-1563), quand l'Église romaine redoute la contagion réformée en Italie. Les quelques procès en matière de foi engagés au concile, et les conflits qu'ils provoquent, permettent de mieux préciser les rapports entre Contre-Réforme, dont l'Inquisition romaine est le bras le plus efficace dans la Péninsule, et Réforme catholique, ou entre la justice et la grâce pour reprendre les termes d'un des «inquisiti». Les actes des deux procès effectués au concile que nous avons conservés donnent un bon exemple de la diversité de la dissidence religieuse italienne, au moment où elle subit la vague de répression qui doit l'étouffer.

\section{Citer ce document / Cite this document :}

Tallon Alain. Le concile de Trente et I'Inquisition romaine. À propos des procès en matière de foi au concile. In: Mélanges de l'Ecole française de Rome. Italie et Méditerranée, tome 106, n¹. 1994. pp. 129-159.

doi : 10.3406/mefr.1994.4310

http://www.persee.fr/doc/mefr_1123-9891_1994_num_106_1_4310

Document généré le 16/10/2015 


\section{LE CONCILE DE TRENTE ET L'INQUISITION ROMAINE}

\section{À PROPOS DES PROCÈS EN MATIÈRE DE FOI AU CONCILE}

Les décrets du concile de Trente sont toujours présentés comme une somme pour l'Église catholique, s'occupant de tous les aspects de sa vie et de ses luttes. Mais curieusement, les pères conciliaires n'ont pas traité d'une des institutions les plus efficaces, au moins dans les pays méditerranéens, de répression de la dissidence religieuse. L'Inquisition, sous sa forme romaine ou ibérique, a échappé au zèle législateur du concile et n'est pas mentionnée, encore moins réformée, par les décrets tridentins. Cette absence n'a guère frappé les historiens du concile, à quelques rares exceptions près'. La distinction entre la Contre-Réforme, dont l'Inquisition est l'institution la plus représentative, et la Réforme catholique, qui a pour charte les décrets du concile, s'est faite spontanément, avant même le livre pionnier d'Hubert Jedin ${ }^{2}$. Il est vrai qu'au concile la prudence a commandé

'Il faut surtout mentionner Luigi Carcereri, dont les travaux sur l'œuvre inquisitoriale du concile ont malheureusement été publiés dans des revues à la diffusion limitée et à l'existence éphémère : L. CARCERERI, Agostino Centurione mercante genovese processato per eresia e assolto dal concilio di Trento (1563), dans Archivio trentino, 21, fasc. 2, 1906, p. 65-99 et Appunti e documenti sull'opera inquisitoriale del concilio di Trento nell'ultimo periodo (1561-1563), dans Rivista tridentina, 10, 1910, p. 65-93. Sur l'Inquisition romaine en général, voir l'évolution de l'historiographie la plus récente dans J. Tedeschi, The Prosecution of Heresy. Collected studies in the Inquisition in early modern Italy, Binghamton, 1991, XXII-417 p. et dans A. Del Col et G. Paolin éd., L'Inquisizione romana in Italia nell'età moderna. Archivi, problemi di metodo e nuove richerche. Atti del seminario internazionale, Trieste, 18-20 maggio 1988, Rome, 1991, 404 p.

${ }^{2}$ H. JEDIN, Riforma cattolica o Controriforma. Tentativo di chiarimento dei concetti con riflessioni sul concilio di Trento, $4^{\mathrm{e}}$ édition, Brescia, 1987, $96 \mathrm{p}$. L'édition originale en allemand date de 1946. H. Jedin n'aborde qu'en passant la question de l'Inquisition. "Sa" Contre-Réforme est nettement plus nordique et surtout allemande, que méditerranéenne. Les nouveaux débats historiographiques sur ces deux notions sont exposés dans P. Prodi, Controriforma elo riforma cattolica : super- 
de ne pas heurter de front les souverains espagnols et portugais, qui tiennent aux statuts privilégiés de leurs Inquisitions ${ }^{3}$. En ce qui concerne l'Inquisition romaine, la bulle Licet ab initio du 21 juillet 1542, qui crée le Saint-Office, commence bien dans son prologue par expliquer que le pape a attendu jusqu'ici en raison de la convocation du concile général, mais que les difficultés pour réunir celui-ci l'ont contraint à agir ${ }^{4}$. Mais ni Paul III, ni ses successeurs n'auraient supporté de voir un concile si péniblement rassemblé toucher à une institution aussi efficace dans la lutte contre les dissidents.

Pourtant, le concile, parfois à son corps défendant, a été obligé d'instruire des procès en matière de foi, empiétant ainsi sur les compétences de l'Inquisition romaine. Des «inquisiti» sont venus demander leur réconciliation à ce qui leur semblait la plus haute autorité dans l'Église, ou du moins la plus indulgente. Ils provoquent alors un réel débat qui n'est pas seulement canonique, mais qui porte sur la conception même du retour des hérétiques repentants au sein du monde catholique de l'époque. Quelle conception de la réconciliation doit-on avoir? Celle de la justice ou celle de la grâce, pour reprendre les termes d'un des «inquisiti»? Entre la ligne dure romaine et celle du concile existent plus que des nuances. Cette opposition, qui n'est pas cependant systématique, traduit assez bien deux conceptions différentes de la Réforme catholique.

amento di vecchi dilemmi nei nuovi panorami storiografici, dans Römische historische Mitteilungen, 31, 1989, p. 227-237.

${ }^{3}$ Cet article, traitant principalement de l'Inquisition romaine, laissera donc de côté les Inquisitions ibériques. La grande question du procès de l'archevêque de Tolède, Bartolome Carranza, a cependant failli être évoquée à Trente. Un agent de l'Inquisition espagnole, Pedro Zumel, est même envoyé au concile pour éviter que ce dernier n'appelle la cause de l'archevêque devant lui ou affirme que son Catéchisme ne contient pas de propositions hérétiques. Voir l'édition de la correspondance de cet agent et des évêques espagnols avec le représentant de l'Inquisition espagnole à Rome dans J. I. Tellechea Idígoras éd., Cartas y documentos tridentinos inéditos (1563), dans Hispania sacra, 16, 1963, p. 191-248. Le risque était important de voir les pères se saisir de l'affaire, si l'on en croit une lettre des légats au cardinal Borromée du 27 mai 1563, où ils le préviennent que certains prélats ont de nouveau présenté une supplique en faveur de l'archevêque de Tolède, Archivio segreto Vaticano (abrégé par la suite en ASV), Concilio 61, fol. 264. Il s'agit peut-être du «Memorial que se dio a los Legados del Concilio por algunos prelados en favor de la causa del arçobispo de Toledo", édité dans J. I. Tellechea Idígoras éd., op. cit., p. 243-244.

${ }^{4}$ Le texte de la bulle est édité dans C. Cocquelines éd., Bullarum privilegiorum ac diplomatum Romanorum pontificum amplissima collectio, t. 4, $1^{\text {ere }}$ partie, Rome, 1745, p. 211-212. Sur le contexte et la signification de la réorganisation de l'Inquisition en 1542, voir G. FRAGNITO, Evangelismo e intransigenti nei difficili equilibri del pontificato farmesiano, dans Rivista di storia e letteratura religiosa, 25, 1989, p. 28. 
Les quelques procès en matière de foi faits au concile ${ }^{5}$ ont un autre intérêt : ils nous montrent quelques personnalités de dissidents italiens et apportent une contribution à l'étude des chemins de l'hérésie dans la Péninsule. Cette contribution reste bien modeste, puisqu'elle ne porte que sur quelques exemples. Mais elle permet d'ajouter une ou deux figures au tableau de la Réforme en Italie.

Le concile s'est réuni pour que tous, catholiques comme hérétiques, puissent venir présenter librement leurs opinions et leurs doléances. Un sauf-conduit garantit le libre retour à ceux qui redoutent le sort de Jean Huss. Mais personne ne se présente lors de la première période tridentine (1545-1547). Le transfert du concile à Bologne en mars 1547 n'encourage pas les dissidents à venir. La présence même du concile semble avoir encouragé l'activité inquisitoriale dans la légation. De nombreux déviants, surtout parmi les religieux mendiants, sont alors pourchassés par le tribunal de Bologne ${ }^{6}$. D'autres viennent spontanément se dénoncer et donner les noms d'autres "mal sentants de la foi». Les légats du concile, notamment Marcello Cervini (le futur et éphémère pape Marcel II), membre de la congrégation du Saint-Office, suivent avec intérêt et encouragent ce zèle. De retour à Rome, Cervini continue de correspondre avec le secrétaire du concile, Angelo Massarelli, au sujet des hérétiques emprisonnés. Il fait même le lien entre l'Inquisition bolognaise et le Saint-Office romain. Un menuisier, qui aggrave son cas en étant relaps, a demandé la clémence des juges romains. Après avoir assisté à la délibération de la congrégation de l'Inquisition sur ce cas, Cervini explique à Massarelli que si l'inquisiteur doit procéder avec douceur avec le coupable, il ne doit pas moins lui

${ }^{5}$ Analysant l'un d'entre eux, John Tedeschi note avec justesse qu'il n'est pas un document inquisitorial, J. TEDESCHI, op. cit., p. 44, n. 61 . Ces procès ne relèvent pas en effet de l'institution inquisitoriale ordinaire, mais d'un tribunal ecclésiastique extraordinaire.

- Sur l'hérésie à Bologne, voir A. Rotondo, Per la storia dell'eresia a Bologna nel secolo XVI dans Rinascimento, II' série, 2, 1962, p. 107-154. Cet article ne note pas l'augmentation de l'activité inquisitoriale pendant le séjour du concile à Bologne, que l'on remarque mieux dans le livre classique de G. BuschBell, Reformation und Inquisition in Italien um die Mitte des XVI. Jahrhunderts, Paderborn, 1910, XXIII-344 p. G. Buschbell utilise la correspondance du cardinal Cervini, conservée dans les Carte Cerviniane de l'Archivio di Stato de Florence. Cette importante activité inquisitoriale ne concerne pas seulement Bologne, mais toute la légation de Romagne. 
démontrer la gravité de son péché, péché que sa lettre ne nous permet pas de connaître? ${ }^{7}$. Mais le concile en tant que tel ne se mêle pas de cette activité des inquisiteurs bolognais ou romains, pas plus qu'il ne vient à l'esprit des victimes de l'Inquisition de demander à être jugées par le concile. A Bologne, terre des États de l'Église, on ne saurait échapper à la juridiction pontificale ordinaire en appelant à une juridiction supérieure. Le concile n'a qu'un rôle stimulant pour l'activité inquisitoriale, il ne peut en aucun cas s'y substituer.

La seconde période tridentine (1551-1552) voit la présence au concile d'ambassadeurs et de théologiens des États protestants allemands. Il ne saurait donc être question de développer en même temps une activité inquisitoriale, sous peine de jeter le soupçon sur la liberté du concile. Les deux sauf-conduits votés par le concile, lors de la treizième session le 11 octobre 1551 et de la quinzième le 25 janvier 1552, sont cependant strictement limités aux Allemands ${ }^{8}$ : les hérétiques italiens ne doivent pas profiter des débats conciliaires pour fuir leur châtiment. De fait, aucun ne cherche à utiliser cette occasion pour se réconcilier à bon compte avec l'Église catholique ou réussir à échapper aux poursuites de l'Inquisition romaine.

C'est seulement lors de la troisième période tridentine (1562-1563) que le problème se pose réellement. Les légats du concile sont alors confrontés à une situation pour eux nouvelle : des personnes ayant à un moment adhéré à des thèses hérétiques viennent obtenir leur réconciliation avec l'Église. On peut se demander pourquoi le problème se pose si tard. L'Inquisition romaine a évolué et le pontificat de Paul IV l'a rendue beaucoup plus redoutable ou au moins redoutée. Les personnes ayant sur la

${ }^{7}$ ASV, Concilio 139, fol. 68, lettre de Cervini à Massarelli, Rome, 17 juillet 1548, "Per la lettera vestra di $\mathrm{X}$ ho inteso con piacere che l'esamine di cotesti heretici incarcerati habbia scoperto paese et giovato a molti altri, che senza aspettar d'esser inquisiti, son venuti a confessar li loro errori et a domandarne penitentia et perdono. Quanto a quel povero falegname, essendosi la sopradetta lettera [letta] in congregatione inanzi alli $R^{m i}$ Deputati, a lor $S S$. $R^{m e}$ pare havendo inteso il caso suo, cioè che sia relapso, che non se li debba cosi facilmente concedere l'assolutione, et però che non se ne debbi dare facultà all'Inquisitore, finche detto falegname non mostra segno d'esser pentito con effetto del error suo, et buon et pronto animo di volerne fare condegna penitentia. Intratanto l'Inquisitore deve procedere verso da lui con lenita, per non desperarlo, et de altra parte metterli inanzi la gravezza del peccato et tenerlo tra penitenti". L'ensemble de la correspondance de Cervini avec Massarelli pendant cette période, contenue dans le même volume de cette série Concilio, s'occupe souvent des «inquisiti" de Bologne.

${ }^{8}$ Concilium Tridentinum (abrégé par la suite en CT), VII, vol. 1, Fribourg-enBrisgau, 1960, p. 207 et 494. 
conscience un délit relevant de l'Inquisition et voulant se mettre en règle, se rendaient sans doute plus volontiers directement au tribunal dans les années 1545-1550, comme cela avait déjà été le cas à Bologne. En 1562, se dénoncer spontanément n'est pas une garantie de rencontrer de l'indulgence. Mais il ne s'agit pas seulement de l'évolution du Saint-Office. Le milieu hérétique italien a lui aussi changé 9 . Le nicodémisme est de plus en plus difficile face à une répression toujours plus efficace. L'exil, possible seulement pour une minorité, n'enthousiasme plus ceux qui voient Bernardino Ochino ou Pier Paolo Vergerio errer de ville en ville, chassés par les nouvelles orthodoxies protestantes et, suivant des rumeurs plus ou moins convaincantes, chercher à se réconcilier avec l'Église romaine ${ }^{10}$. Les possibilités d'une réconciliation avec l'Église catholique sans risquer de perdre ses biens, sa liberté ou sa vie, ne peuvent que séduire ceux qui cherchent désormais avant tout la tranquillité.

Le premier problème se pose à Trente même, terre d'Empire où l'Inquisition sous sa nouvelle forme n'a pas été installée. À peine arrivés, les légats du concile sont saisis par le gardien et le prieur du couvent franciscain observant de San Bernardino de la question des nombreux excommuniés, qui ont lu en toute bonne foi des livres prohibés par l'Index publié par Paul IV en 1559 et qui, apprenant leur faute, n'osent plus s'approcher des

${ }^{9}$ Sur l'évolution de l'historiographie depuis les œuvres majeures de Delio Cantimori, voir A. J. SchutTe, Periodization of Sixteenth-Century Italian Religious History: The Post-Cantimori Paradigm Shift, dans Journal of Modern History, 61, 1989, p. 269-284 et le dossier spécial de Studi storici, 34, 1993, fasc. 4, qui a pour titre Delio Cantimori. Gli eretici del Cinquecento e la crisi europea tra le due guerre. Voir aussi les deux livres très récents de S. CAPONETTO, La Riforma protestante nell'Italia del Cinquecento, Turin, 1992, 526 p. et de M. FIRPO, Riforma protestante ed eresie nell'Italia del Cinquecento, Bari, 1993, 206 p. Ces deux livres comportent une bibliographie très complète.

${ }^{10}$ D'après le témoignage plus que suspect du polémiste catholique Florimond de Raemond, Ochino, quittant Bâle et apprenant que le cardinal de Lorraine, rentrant du concile, passe non loin de là, va le supplier d'intercéder pour lui auprès du SaintSiège pour obtenir son pardon. Le cardinal de Lorraine le repousse, F. DE RAEMOND, Histoire de la naissance, progrez et decadence de l'heresie de ce siecle, Rouen, Estienne Vereul, 1622, p. 294. En ce qui concerne Pier Paolo Vergerio, le nonce en Allemagne Delfino a une série d'entretiens avec lui en avril et mai 1561, qui laissent espérer le retour de ce dernier à l'Église, par le moyen du cardinal de Mantoue, président du concile. Charles Borromée prend très au sérieux l'affaire, qui ne débouchera sur rien. Voir S. Steinherz éd., Nuntiaturberichte aus Deutschland 1560-1572. Erster Band: Die Nuntien Hosius und Delfino, Vienne, 1897, p. 356 sq., lettre de Delfino à Borromée, Schwarzach, 13 mai 1561 et J. Susta éd., Die römische Kurie und das Konzil von Trient unter Pius IV. Actenstücke zur Geschichte des Konzils von Trient, 1 , Vienne, 1904, p. 28, lettre de Borromée au cardinal de Mantoue, Rome, 30 mai 1561. 
sacrements" ${ }^{11}$ Les légats demandent alors à Rome le pouvoir de les absoudre, qui leur est accordé sans la moindre difficulté' ${ }^{12}$. L'absolution collective est donnée le jour de la Pentecôte $1561^{13}$. Le péché est considéré comme d'autant moins grave que tous s'accordent pour juger l'Index de Paul IV beaucoup trop rigoureux. Le concile doit même lui substituer un nouvel Index plus réaliste ${ }^{14}$.

Plus délicate est la demande de deux dominicains polonais revenant de Bologne pour rentrer dans leur pays après avoir reçu leurs grades universitaires. Ils suggèrent qu'en Pologne beaucoup d'hérétiques retourneraient volontiers à l'Église romaine si on leur épargnait l'humiliation de la pénitence publique. Ils ont d'abord sollicité le grand Inquisiteur, Michele Ghislieri, cardinal d'Alexandrie, qui a refusé. Cette position intransigeante est bien dans la manière du futur Pie $\mathrm{V}$, mais les légats ne la partagent pas. Ils appuient la demande auprès du cardinal Borromée ${ }^{15}$. Là encore, le pape accepte volontiers de donner aux légats, et plus particulièrement au cardinal Hosius, mieux qualifié pour une question qui concerne ses compatriotes, la faculté de désigner deux ou trois religieux qui pourraient absoudre secrètement certains repentis. Il suggère juste que le nonce pourrait tout aussi bien remplir cet office ${ }^{16}$. Le bref, donnant aux légats la faculté d'absoudre les hérétiques de l'Empire, de Pologne et des pays septentrionaux, est expédié le 24 mai et permet de renvoyer les deux dominicains dans leur pays avec la délégation au nonce des pouvoirs des légats ${ }^{17}$.

"J. Susta éd., op. cit., 1, p. 17, lettre des légats au cardinal Borromée, Trente, 8 mai 1561. Les légats donnent comme exemple ceux qui se trouvent excommuniés pour avoir lu un livre où se serait trouvé une lettre préface d'Érasme. On sait qu'Érasme, entièrement prohibé par Paul IV, fut déclassé par le concile de Trente et que seule une partie de ses œuvres fut condamnée.

${ }_{12} \mathrm{~J}$. Susta éd., op. cit., 1, p. 19, lettre de Borromée aux légats, Rome, 17 mai 1561.

${ }^{13}$ ASV, Concilio 60, fol. 20, lettre des légats à Borromée, Trente, 26 mai 1561.

${ }^{14}$ Le concile débat de cette question peu de temps après sa réouverture le 18 janvier 1562. Malgré les réticences de certains prélats, dont les archevêques de Grenade et de Braga, craignant peut-être de voir les privilèges des Inquisitions de leurs pays mis en cause, la majorité des pères accepte que les légats nomment une commission chargée de réformer l'Index de Paul IV, voir CT VIII, p. 306-325. Sur les débats tridentins sur l'Index, voir D. DE Pablo Maroto, El indice de libros prohibidos en el concilio de Trento, dans Revista española de teologí, 36, 1976, p. 39-64, et J.M. De Bujanda éd., Index de Rome. 1557, 1559, 1564, Sherbrooke-Genève, 1990, p. 59 sq.

${ }^{15} \mathrm{~J}$. Susta éd., op. cit., 1, p. 19, lettre des légats à Borromée, Trente, 12 mai 1561.

${ }^{16} \mathrm{~J}$. Susta éd., op. cit., 1, p. 21, lettre de Borromée aux légats, Rome, 24 mai 1561.

${ }^{17}$ ASV, Concilio 60, fol. 24, lettre des légats à Borromée, Trente, 2 juin 1561. Voir la lettre de remerciement de l'évêque de Camerino, nonce en Pologne, datée de Cracovie du 25 juin 1561 dans CT VIII, p. 229. Le texte de cette faculté déléguée au 
La facilité avec laquelle sont résolues ces deux questions n'est guère étonnante. Dans le cas de Trente comme dans celui de la Pologne, il n'y a aucun conflit de juridiction entre le concile et une Inquisition romaine qui, malgré ses prétentions universelles, n'exerce réellement son pouvoir qu'en Italie. La mansuétude romaine s'explique aussi facilement à la veille de l'ouverture d'un concile où sont encore attendus des représentant protestants. Rome veut croire que nombreux seront ceux qui demanderont leur réconciliation et ne veut décourager personne en se montrant trop sévère. Borromée écrit d'ailleurs au cardinal de Mantoue, président du concile, le 9 avril 1561 : «Quant à ce que nécessite la réduction d'un quelconque hérétique, je certifie à votre Seigneurie Illustrissime que tout ce que vous ferez sera toujours approuvé par Notre Seigneur et que dans ce cas comme dans des cas similaires qui tournent au bénéfice des âmes et au service de Dieu, vous pouvez user librement de l'autorité qui vous a été donnée par Sa Béatitude sans attendre d'elle une nouvelle commission ${ }^{18}$.

Les légats restent cependant pointilleux sur le plan canonique. Quand un dominicain allemand apostat vient leur demander l'absolution, ils relisent avec attention les termes du bref et découvrent qu'ils n'ont pas le pouvoir d'absoudre une personne déjà poursuivie par un tribunal inquisitorial. Ils demandent donc à Rome de modifier le bref, en limitant l'exclusion aux seules personnes poursuivies par l'Inquisition romaine. Ils justifient de façon intéressante cette modification en expliquant que comme l'Inquisition romaine prévaut sur tous les autres tribunaux, il ne serait pas normal que la juridiction du concile soit contestée par ces tribunaux inférieurs ${ }^{19}$. Cette affirmation de la supériorité d'une juridiction conciliaire, qui ne le cède qu'à la juridiction romaine, est lourde de conséquences, car elle

nonce de Pologne se trouve dans ASV, Concilio 146, fol. 442-444 vo, "Substitutio episcopi Camerinen. Nuncii Apostolici in Polonia, super recipiendis ad gremium Ecclesiae haereticis non inquisitis. Per Illmox DD. legatos concilii, 2 junii $1561 »$. Les légats donnent le texte du bref les autorisant à absoudre les personnes hérétiques de ces régions "dummodo per alios inquisitae non fuerint" (fol. 443), daté du 24 mai 1561.

18 «Quanto a quel che bisognasse per la reduttione di qualche heretico certifico

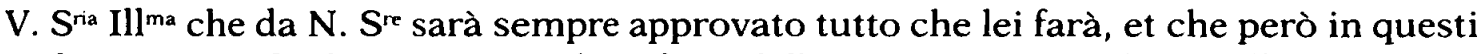
o altri casi simili che tornano in beneficio del'anime et servitio di Dio ella può usare liberamente del'autorità datagli da $\mathrm{S}$. $\mathrm{B}^{\text {ne }}$ senza aspettarne da lei nuova commissione.» J. Susta éd., op. cit., 1, p. 10.

${ }_{19}$ «Perche si come è honesto che a quel santo ufficio tutti gli altri tribunali d'Inquisitione cedano, cosi non par' bene che con questo nostro competano gli inferiori", ASV, Concilio 60, fol. 63, lettre des légats à Borromée, Trente, 31 juillet 1562. 
peut conduire à la reproduction de ce qui s'était passé à Bâle, où le concile s'était peu à peu substitué aux juridictions ordinaires de l'Église. Pourtant, là encore, le pape se prête rapidement aux désirs des légats et envoie un bref modifié selon leurs vœux ${ }^{20}$.

Après la réouverture du concile, la discussion sur le texte du saufconduit à publier modifie imperceptiblement ces rapports si faciles. Le 2 mars 1562, lors de la deuxième session sous Pie IV (dix-huitième du concile), les légats proposent de reprendre les termes du sauf-conduit donné pour l'Empire lors de la deuxième période tridentine, en l'étendant aux autres nations. Cette extension cependant est limitée aux pays "dans lesquels se prêche ou s'enseigne ou se croit, publiquement et impunément, le contraire de ce que pense la sainte Église romaine $"{ }^{21}$. Ce sauf-conduit laisse quelques zones d'ombres. La France de l'édit de janvier est-elle comprise parmi ces pays hérétiques ${ }^{22}$ ? Comment faire pour ceux qui souhaitent se réconcilier avec l'Église après avoir été convaincus au concile de la vérité des dogmes catholiques, scénario dont rêvent les pères conciliaires ${ }^{23}$ ? Les Inquisitions sont très fermes pour éviter tout empiétement

${ }^{20}$ "Con questa le SS. VV. Illme haveranno il breve de le loro facultà di assolvere Inquisiti riformato, et ampliato in quel modo medesimo che esse ricordato", ASV Concilio 50, fol. 38, lettre de Borromée aux légats, Rome, 9 août 1561. Le texte du bref réformé est édité dans CT VIII, p. 242-3.

${ }^{21}$ "In quibus publice et impune praedicatur vel docetur sive creditur contrarium eius, quod sancta Romana sentit ecclesia», CT VIII, p. 375.

${ }^{22}$ Dans une lettre du 6 avril 1562, alors que la guerre civile commence, Borromée assure le nonce en France que les ministres peuvent venir sans aucune crainte sous la sauvegarde du sauf-conduit, J. Susta éd., op. cit., 2, p. 430. Le texte du saufconduit fut édité, notamment à Lyon par l'imprimeur Michel Jove en 1563, sans doute après la fin de la guerre civile. Les prélats français présents à Trente tiennent beaucoup à ce que ce sauf-conduit ne reste pas lettre morte. Le cardinal de Lorraine conseille ainsi au pape, par l'intermédiaire de l'évêque de Viterbe Sebastiano Gualterio, d'interrompre les procédures en cours au Saint-Office contre Jean de Monluc, évêque de Valence sympathisant de la Réforme. H. JEDIN, Krisis und Wendepunkt des Trienter Konzils, Würzburg, 1941, p. 134, lettre de Gualterio à Borromée, Trente, 9 décembre 1562, en chiffre : "Quanto al vescovo di Valenza gli pare che sia di bisogno di andarci dentro con gran rispetto, et che facendo egli la sua confessione di fede, ne dando qui occasione di scacciarlo, non fosse bene d'innovar cosa alcuna, perche gl'Ugonotti non desiderarebonno altra cosa più che haver qualche colorata occasione da poter dire che fosse stato rotto loro il salvocondutto". Cet avertissement n'empêche pas Pie IV d'autoriser le Saint-Office à poursuivre les évêques français suspects d'hérésie (dont aucun ne se trouve au concile), A. DEgert, Procès de huit évêques français suspects de calvinisme, dans Revue des questions historiques, 76, 1904, p. 61-108.

${ }^{23}$ La lettre des légats annonçant la venue d'un marchand génois demandant sa 
sur leur juridiction. Dès le mois de janvier, les légats se sont demandé comment éviter de déplaire aux inquisiteurs romains et ibériques et en même temps de «montrer la bénignité et la clémence très grandes de Sa Sainteté et inviter tout le monde à venir librement à ce saint concile réuni par Sa Béatitude, et espérer de sa très grande bonté la miséricorde et le pardon „24. Les négociations sont difficiles et les légats demandent à Rome de les aider à concilier les deux objectifs de ménager les Inquisitions romaine et ibérique et de sauvegarder la crédibilité et la dignité du concile ${ }^{25}$. Une commission conciliaire restreinte se réunit le $1^{\text {er }}$ mars 1562 . Elle est composée de l'archevêque de Rossano Giovanni Battista Castagna, de l'évêque de Lérida Antonio Agustino, de celui de Viesti Ugo Buoncompagni (le futur Grégoire XIII), de l'auditeur de la Rote Gabriele Paleotti et du promoteur du concile Giovanni Battista de Castello ${ }^{26}$. Les différents textes que la commission propose ne suffisent pas pour résoudre le problème. Le compromis final est de ne pas traiter la question de la réconciliation des hérétiques par le concile dans le texte du sauf-conduit, mais de procéder au cas par cas. En ce qui concerne les justiciables des Inquisitions ibériques, le concile décidera, si le cas se présente, si le pénitent doit être jugé par l'Inquisition concernée ou par une délégation de deux évêques du même pays. Cette solution ne paraît cependant toujours pas satisfaisante aux légats en ce qui concerne l'Inquisition romaine et ils l'écrivent à Borromée : nous avons besoin de votre avis "étant plus que sûrs que nombre de ceux qui sont poursuivis par l'Inquisition romaine préféreront mourir damnés que de se rendre à ce tribunal, et viendraient sans doute volontiers ici, espérant trouver en nous cette miséricorde et cette clémence que la sainte Église promet aux pénitents et qui est digne d'un tel concile, réuni pour le salut de tous. Les pères, pour dire la chose comme elle est à Votre Seigneurie Illustrissime et Révérendissime, inclinent tous à la clémence et désirent qu'on en use avec tous, qu'ils soient poursuivis par l'Inquisition de n'importe quel lieu pourvu qu'ils se trouvent en liberté, car il leur paraît dur que le concile

réconciliation est révélatrice : «È comparso qui un gentilhuomo Genovese, inquisito dalla inquisitione di Genova, per mezzo del quale, si come intendemo, si potria sperare di ridurre alla riconciliatione molti suoi complicin, J. Susta éd., op. cit., 3, p. 155.

24 "Mostrare la molta benignità et clementia di S. S. 'à, et invitare tutto'l mondo a venire liberamente a questo santo concilio congregato da $S$. $B^{\text {ne }}$, et a sperare misericordia et perdono da la molta bontà sua», J. Susta éd., op. cit., 1, p. 149, lettre des légats à Borromée, Trente, 4 janvier 1562.

${ }^{25}$ "Havemo non picciolo bisogno d'esser aiutati", J. Susta éd., op. cit., 2, p. 36, lettre des légats à Borromée, Trente, 25 février 1562.

${ }^{26}$ CT III, 1, p. 279. 
universel doive repousser qui que ce soit, qui pour se sauver fait recours à lui ${ }^{27}$.

Cette lettre des légats prouve le traumatisme qu'a laissé en Italie le pontificat de Paul IV, y compris dans les rangs catholiques. Sans trop se soucier des «inquisiti» espagnols ou portugais ${ }^{28}$, les légats se font l'écho de l'opinion commune des Italiens qui ont vécu des années de terreur entre 1555 et 1559, quand même des cardinaux étaient soupçonnés, voire inquiétés par l'Inquisition romaine. Ils opposent à cette logique de répression une logique de clémence, non seulement pour des raisons conjoncturelles et de séduction de l'adversaire, mais aussi pour défendre la dignité du concile. Cet argument montre un conciliarisme latent, opposant à l'autoritarisme arbitraire de l'institution romaine un concile qui incarne la vertu chrétienne de miséricorde et l'universalisme d'une assemblée "réunie pour le salut de tous" ${ }^{29}$. Ce genre de position ne peut que heurter une Inquisition romaine encore très largement dominée par Michele Ghislieri, le cardinal d'Alexandrie héritier de l'esprit du pontificat Carafa $^{30}$.

Le cardinal Borromée répond aux légats qui préfèrent éviter de prendre seuls une décision ${ }^{31}$ en précisant la position romaine : les hérétiques doivent pouvoir venir et repartir librement, mais il n'est pas question de leur assurer une quelconque absolution au concile même. Il assure cependant les légats que si le cas se présente, le pape est prêt à faire preuve

${ }^{27}$ "Essendo noi più che sicuri che molti inquisiti a Roma si lascerianno più tosto morire dannati che ridursi a quel tribunale, et qua per aventura verrebbono volontieri, sperando di trovarci quella misericordia et clemenza che la Santa Chiesa promette a penitenti, et ch'è degna d'un cosi fatto concilio, congregato per la salute di tutti. Questi Padri per dir a V. Ill ${ }^{\text {ma }}$ et $R^{\text {ma }} S^{\text {ra }}$ la cosa coma stà, inclinano tutti alla clemenza, et desiderano che s'usi con tutti, sieno inquisiti dove si voglia purchè si trovino in libertà, parendo lor duro che'l Concilio universale habbia da chiudere le braccia a qualunque ci sia, che per salvarsi si ricorra allui», J. Susta éd., op. cit., 2 , p. 42-43, lettre des légats à Borromée, Trente, 5 mars 1562.

${ }^{28}$ Leur éventuelle venue au concile reste en effet plus que théorique et il n'est pas question de s'aliéner Philippe II dès le début du concile en entravant de quelque manière que ce soit l'action de l'Inquisition espagnole, qui s'est lancée depuis quelques années dans une violente répression anti-protestante.

${ }^{29}$ Les légats envoient ainsi le texte du sauf-conduit à tous les nonces en leur demandant de le diffuser le plus largement possible "acciochè ognuno sappia essere aperta la via a chi vuol ritornare", J. Susta éd., op. cit., 2, p. 46, lettre des légats à Borromée, Trente, 9 mars 1562.

${ }^{30}$ Sur l'activité du futur Pie V comme grand Inquisiteur, voir la récente biographie de N. Lemaitre, Saint Pie V, Paris, 1994, p. 61-66.

${ }^{31} \mathrm{~J}$. Susta éd., op. cit., 2, p. 51, lettre des légats à Borromée, Trente, 12 mars 1562. 
$\mathrm{d}^{\text {'indulgence }}{ }^{32}$. Les légats répondent en réaffirmant leurs positions ${ }^{33}$. Cependant, le flou de ces échanges laisse une certaine place à une attitude pragmatique, que souhaitent les légats comme Borromée, mais pas de la même manière. Le résultat de ce compromis tacite est que les légats ne touchent pas à la juridiction des Inquisitions ibériques, mais se sentent plus libres vis-à-vis de l'Inquisition romaine ${ }^{34}$.

Mais dès que les premiers cas se présentent, le pragmatisme cède et des positions plus nettes se dessinent. Un des membres du cercle de Modène, Lodovico Castelvetro, traducteur en italien des Loci communes de Mélanchthon, est recherché par l'Inquisition romaine ${ }^{35}$. Il s'est enfui l'hiver 1560 pour se réfugier à Chiavenna dans la Valteline soumise aux Grisons. De là, il demande à ce que son cas soit jugé par le concile. La réponse de Borromée est nette : Castelvetro ne peut être jugé qu'à Rome et la seule chose qu'on peut lui promettre est l'indulgence, voire une abjuration secrète $^{36}$. Plus délicat encore est le cas du patriarche d'Aquilée, Giovanni Grimani ${ }^{37}$. L'Inquisition romaine l'accuse d'avoir soutenu des thèses héré-

32 J. Susta éd., op. cit., 2, p. 58-59, lettre de Borromée aux légats, Rome, 14 mars 1562.

${ }^{33}$ J. Susta éd., op. cit., 2, p. 62-63, lettre des légats à Borromée, Trente, 23 mars 1562.

${ }^{34}$ Soulagé, l'évêque de Lérida Antonio Agustino, membre de la commission restreinte du $1^{\text {er }}$ mars, écrit le 16 mars à l'ambassadeur espagnol à Rome, Francisco Vargas : «Paresce que cumple a la honra del concilio reconciliar qualquir genero de personas, y a esto inclinan todos los obispos no Españoles y aun alcun dellos; por otra parte el reçelo, que no avian de sconçertar las inquisiciones de España y Portugal y offender a tales dos principes, haze, que los legados no se sepan determinar y andan buscando medios, y al fin creo, que paran en dilatar el negocio y remediar a los, que vinieren particularmente de Italia, dando nominatim el salvo condutto al que lo pidiere. Para este effecto, como me dizen, que los obispos de Modena y Cremona y el arçobispo de Genova tienen ya de sus diocesis fugitivos, que vendran a reconciliarse», CT IX, p. 1129.

${ }^{35}$ Il figure dans un Compendium Processum sancti officii Romae sous ces accusations : "Qui scit res Moroni", "ex primo teste in informatione, et ex ejus relatione de seductione Moroni", "prima haereticus", "Lutheranus», C. Corvisieri éd., Compendio dei processi del Santo Uffizio di Roma da Paolo III a Paolo IV, dans Archivio della Società romana di storia patria, 3, 1880, p. 278. Pour un résumé de la vie de Castelvetro, voir S. CAPonetro, op. cit., p. 312. Après une vie d'errance à Genève, Lyon, Vienne et Chiavenna, Castelvetro meurt toujours en exil en 1571. L'article d'A. Rotondo, Esuli italiani in Valtellina nel Cinquecento, dans Rivista storica italiana, 88, 1976, p. 756-791, ne traite qu'en passant de Castelvetro et s'occupe surtout de la période post-conciliaire.

${ }^{36} \mathrm{~J}$. Susta éd., op. cit., 1, p. 76.

${ }^{37}$ Voir L. CARCERERI, Giovanni Grimani patriarca d'Aquileia, imputato di eresia e assolto dal Concilio di Trento, Rome, 1907, 110 p. 
tiques sur la prédestination dans une lettre au dominicain Maracco du 17 avril 1549. La République de Venise, qui protège Grimani, demande à ce qu'il soit jugé par le concile. Là encore, le refus de Rome est net ${ }^{38}$. Le SaintOffice envoie même au patriarche une citation à comparaître personaliter, que le nonce à Venise ne doit utiliser que si Grimani persiste dans sa volonté d'aller devant le concile ${ }^{39}$. Mais Pie IV n'est pas en position de force et essaye de transiger : Grimani ne serait plus jugé par l'Inquisition mais par le Sacré Collège ${ }^{40}$. Ces efforts se heurtent à la volonté vénitienne.

Grimani part bien pour Trente en juin 1563. Les légats, sous la pression des ambassadeurs vénitiens ${ }^{41}$, finissent par accepter d'évoquer sa cause. Il est jugé par une commission nommée par les légats le 31 juillet 1563, qui l'absout de tout soupçon d'hérésie le 17 septembre $1563^{42}$.

Il était difficile pour Rome de refuser que le concile puisse juger un père conciliaire. Même si le procès de Grimani est bien un procès en matière de foi, le concile n'empiète pas réellement sur les compétences de l'Inquisition romaine. Le Saint-Office en effet est le tribunal suprême en ce qui concerne l'hérésie, mais il n'a jamais prétendu être le seul organe judiciaire compétent en ce domaine ${ }^{43}$. Il n'en reste pas moins que le pape, contraint de faire une exception en raison des pressions vénitiennes, n'a pas l'intention de voir se renouveler ce type de jugement par le concile.

Tous les «inquisiti» n'ont pas la chance de voir une grande puissance

${ }^{38}$ Borromée écrit au nonce à Venise, Ippolito Capilupo, évêque de Fano, le 21 mars 1562, qu'après avoir consulté le Saint-Office, le pape lui demande de dire à la République "che essendo il Patriarca partito di qua senza licenza, in modo che si può dire fuggito da questo Tribunale, non può $S$. $S^{\text {ta }}$ con honor di detto officio et suo proprio consentire ch'egli vada a Trento, et non solo non lo consente, mà se potessse impedirlo lo impedirebbe. Et caso ch'egli vi voglia pur andare, S. $S^{\text {ta }}$ abandonnera la sua prottetione", ASV, Nunziature di Venezia 2, fol. 55. Le cardinal ajoute de façon bien peu crédible que le concile sera peut-être plus sévère que le Saint-Office. Les légats sont informés le 15 mars 1562 de la volonté de Grimani de se faire juger à Trente et du refus catégorique de Pie IV. Ils font dire alors à Grimani de ne pas venir "perchè non seria stato ascoltato", CT III, 1, p. 127.

${ }^{39}$ ASV, Nunziature di Venezia 2, fol. 57, lettre de Borromée à Capilupi, Rome, 11 avril 1562.

${ }^{40} \mathrm{Ibid}$., fol. $57 \mathrm{v}^{\circ}$, lettre du 18 avril 1562.

${ }^{41}$ Voir leur lettre à Borromée du 22 juin 1563, J. Susta éd., op. cit., 4, p. 93-5.

${ }^{42}$ CT IX, p. 681 et 828 . Les différents votes des membres de la commission se trouvent dans ASV, Concilio 10, fol. 354.

${ }^{43}$ Il est étonnant de voir que les historiens du droit et les canonistes ont peu travaillé sur les compétences juridiques du Saint-Office et leur évolution lors de la Contre-Réforme. L'article "Saint-Office" du Dictionnaire de droit canonique est plus que succinct. Il est vrai que la fermeture des archives de l'actuelle Congrégation pour la doctrine de la foi ne facilite guère la tâche... 
catholique se préoccuper de leur sort. Au moment même où le pape se résigne à laisser juger Grimani par le concile, un dominicain apostat, Pietro Scotto, se voit refuser toute possibilité d'être jugé ailleurs qu'à Rome $^{44}$. L'Inquisition romaine s'oppose fermement au concile sur deux cas : celui d'un marchand génois domicilié à Lyon, Agostino Centurione, et celui d'un notaire de Bergame, Vincenzo Marchesi. Centurione, converti au calvinisme pendant son séjour en France et recherché par l'inquisiteur de Gênes, arrive à Trente en janvier 1563 et demande à être réconcilié. L'archevêque de Gênes Agostino Salvago étant présent au concile, les légats ne font aucune difficulté pour constituer un tribunal, en lui adjoignant deux autres prélats, Egidio Foscarari, évêque de Modène et Ugo Buoncompagni, évêque de Viesti, puis peu de temps après Leonardo Marini, archevêque de Lanciano ${ }^{45}$. Mais le Saint-Office s'inquiète et demande plus de renseignements, suggérant même que Centurione devrait plutôt être jugé à Gênes par l'inquisiteur du lieu. Les légats répondent avec un certain agacement qu'ils ne comprennent pas pourquoi l'inquisiteur serait plus qualifié que l'archevêque lui-même. Ils acceptent cependant de suspendre l'instruction du procès, mais rappellent que la composition de la commission chargée de juger Centurione est telle qu'elle ne devrait laisser aucun soupçon ${ }^{46}$. Une lettre explicative envoyée au Saint-Office par les légats ${ }^{47}$ calme les inquiétudes romaines et permet la reprise du procès ${ }^{48}$.

Plus dure encore est l'opposition de l'Inquisition pour la réconciliation d'un notaire de Bergame, Vincenzo Marchesi ${ }^{49}$. Ce dernier a aggravé son

${ }^{44}$ ASV, Concilio 51, fol. 121, lettre de Borromée au cardinal Simonetta, Rome, 7 juillet 1563 .

${ }^{45}$ J. Susta éd., op. cit., 3, p. 155, 186 et 261, lettres des légats à Borromée, Trente, 7 et 28 janvier, 8 mars 1563 .

46 «Havendo il detto Genovese havuto ricorso a noi, commettemmo la causa sua qui et la commissione fu fatta da noi con tal consideratione che tenemmo per certo che non dovesse potere dispiacere a persona, poichè l'arcivescovo di Genova è il pastore di quel tale, l'arcivescovo di Lanzano et il vescovo Buoncompagno sono della inquisitione di Roma et il vescovo di Modena è dotto et da bene», J. Susta éd., op. cit., 3, p. 261, lettre des légats à Borromée, Trente, 8 mars 1563.

${ }^{47}$ Cette lettre du 8 mars 1563 est éditée par L. Carcereri, Agostino Centurione, op. cit., p. 77.

${ }^{48} \mathrm{~J}$. Susta éd., op. cit., 3, p. 280 , lettre de Borromée aux légats, Rome, 17 mars 1563. L'inquiétude du Saint-Office peut aussi s'expliquer par les difficultés de faire accepter l'Inquisition romaine par la République de Gênes. Voir G. BERTORA, Il tribunale inquisitorio di Genova e l'Inquisizione romana nel'500 alla luce di documenti inediti, dans La Civiltà cattolica, 104, 1953, p. 173-187.

${ }^{49}$ Ce cas a été étudié par L. CARCERERI, Appunti e documenti sull'opera inquisitoriale del concilio di Trento nell'ultimo periodo (1561-1563), dans Rivista tridentina, 10, 
cas en étant relaps et en ayant réussi à s'échapper des prisons de l'Inquisition à Milan. Il arrive à Trente où il remet une supplique aux légats, leur demandant de le réconcilier avec l'Église ${ }^{50}$. Les légats demandent alors au pape un nouveau bref leur permettant de le juger. Borromée accepte, mais rappelle qu'un bref similaire a été fait à l'ouverture du concile ${ }^{51}$. Après quelque difficulté, le bref envoyé le 18 septembre 1563 doit permettre aux légats de faire juger Vincenzo Marchesi, mais ils se heurtent à l'obstruction de l'inquisiteur de Milan, qui refuse d'envoyer à Trente les pièces du procès, arguant du fait qu'il s'agit d'un cas réservé à l'Inquisition romaine ${ }^{52}$. Les légats protestent vivement ${ }^{53}$ et le pape lui-même doit intervenir pour convaincre le grand Inquisiteur, Michele Ghislieri, d'envoyer au concile les

1910, p. 65-93. On ignore le délit commis par Marchesi. Peut-être faisait-il tout simplement partie de l'entourage de l'évêque de Bergame, Vittorè Soranzo, une des figures de proue des spirituali qui fut privé de son évêché en 1558, à la suite d'un procès devant le Saint-Office : cf. P. PASchINI, Un vescovo disgraziato nel Cinquecento italiano : Vittore Soranzo, dans Tre ricerche sulla storia della Chiesa nel Cinquecento, Rome, 1945, p. 89-151, et L. CHIODI, Eresia protestante a Bergamo nella prima metà del'500 e il vescovo Vittore Soranzo. Appunti per una riconsiderazione storica, dans Rivista di storia della Chiesa in Italia, 35, 1981, p. 456-485.

${ }^{50}$ Le texte perdu de la supplique est tel "che essendo stata letta da noi ci ha veramente mossi a pietà et compassione di lui", lettre des légats à Borromée, Trente, 19 août 1563, éditée par L. CarCERERI, op. cit., p. 91.

${ }^{51}$ ASV, Concilio 27, fol. 248, lettre de Borromée aux légats, Trente, 28 août 1563.

52 Texte de la lettre de l'inquisteur de Milan dans L. Carcereri, op. cit., p. 92. L'inquisiteur de Bergame, un Augustin du nom de Fra Paolo da Terzo, envoie sans faire de problèmes les pièces demandées, mais il en profite dans une lettre du 15 octobre 1563, pour demander aux légats un vrai statut financier pour l'Inquisition : il les supplie "che atteso la grande necessità et utilità del nostro Santo Ufficio della Inquisitione nella Chiesa d'Iddio, sue Illme et $\mathbf{R}^{\text {me }} \mathbf{S}^{\text {rie }}$ vogliano di quello ricordarsi nelle provisioni che si hano fare nella prossima sessione circa delli altri gradi overo uffici ecclesiastici, ordinando che il detto Santo Ufficio, il quale universalmente (dalla Spagna fuori) è poverissimo, habbia qualche entrata onde puossa sostentarsi et essequirsi, rinnovando li sacri canoni et leggi da nostri maggiori in favor di quello promulgato. Altrementi io temo che in breve, tanto moltiplicarano gli perfidi eretici, etiandio in queste nostre parti d'Italia, che puoi nè le sue, nè altre ordinarie provisioni sarano sofficienti a comprimere il loro orgoglio", ASV, Concilio 30, fol. 361.

${ }^{53}$ ASV, Concilio 61, fol. 610, lettre des légats à Borromée, Trente, 28 octobre 1563. Les légats veulent absoudre Marchesi à Trente "per mostrare essempio di misericordia alle pecore smarrite che ritornano a noi, perciò che c'è data speranza che spedito che sia costui forse ne verranno degli altri». Ils refusent l'idée de l'avoir fait attendre deux ou trois mois pour rien : "Sarebbe con poca autorità di questo sacro concilio et con detrimento di quelle anime, che forse ricorrerrano qui a penitenza quando siamo sicure della facultà nostra in ispedirle». 
actes romain du procès ${ }^{54}$. On ne connaît pas la sentence que le concile, sur le point de se terminer, a pu rendre dans ce cas précis.

Tous ces exemples prouvent que si le concile a pu se prononcer dans des procès en matière de foi, voire réconcilier certains hérétiques, il l'a fait contre la mauvaise volonté évidente de l'Inquisition romaine. Cette institution se méfie des pères conciliaires, volontiers soupçonnés de flirter avec l'hérésie ${ }^{55}$. Les groupes des spirituali, qui avaient été nombreux à Trente lors de la première période conciliaire, sont devenus des suspects depuis le pontificat de Paul IV. La présence d'hérétiques dans l'entourage des légats de cette première période, notamment auprès du cardinal Reginald Pole, est désormais tout à fait évidente pour les membres du Saint-Office ${ }^{56}$. Ces derniers ont en outre hérité de leur protecteur Paul IV un certain mépris pour le milieu conciliaire ${ }^{57}$. La nomination du cardinal Giovanni Morone comme président du concile après la mort du cardinal de Mantoue le 2 mars 1563 ne fait qu'accentuer cette méfiance: Morone, bien que disculpé par Pie IV, a

${ }^{54}$ Lettre de Borromée aux légats, Rome, 6 novembre 1563, éditée dans L. CARCERERI, op. cit., p. 92.

${ }^{55}$ La crainte des inquisiteurs rejoint l'espoir des protestants : un avis de Venise du $1^{\text {er }}$ décembre 1545 envoyé à Henry VIII annonce que les évêques réunis à Trente, lisant les livres des réformateurs pour mieux les condamner, ont été convaincus par ces mêmes livres et de persécuteurs sont devenus des défenseurs de l'Évangile, J. Gairdner et R. H. Brodie, éds., Letters and papers, foreign and domestic, of the reign of Henry VIII, 20 (1545), vol. 2, Londres, 1907, p. 457. Le plus paradoxal est que cette nouvelle, pour le moins exagérée, ne pourrait guère concerner que le cercle réuni autour du cardinal Reginald Pole, ennemi juré du roi d'Angleterre, mais partisan d'un évangélisme érasmien qui a pu apparaître proche des thèses protestantes.

${ }^{56}$ Le cas le plus évident est celui d'un théologien catalan, Juan Morillo, venu à Trente en 1545 avec l'évêque de Clermont Guillaume Duprat. Morillo passe au service du cardinal Pole, puis retourne en France où il se convertit au calvinisme. Il finit sa vie comme ancien de l'Église réformée française de Francfort. Voir l'article de A. G. Kinder, Juan Morillo. Catholic Theologian at Trent, Calvinist Elder in Frankfurt, dans Bibliothèque d'humanisme et de Renaissance, 38, 1976, p. 345-351. Les Inquisitions espagnole et romaine, quand elles ont à interroger une personne ayant participé au concile, ne manquent pas de lui demander si elle a été en relation avec Morillo ou avec le cercle de théologiens autour de Pole. C'est le cas pour Bartolome Carranza comme pour Pietro Carnesecchi : I. Tellechea Idígoras éd., Fray Bartolome Carranza. Documentos históricos, II, 2 (Archivio documental español, 19), Madrid, 1963, p. 561, 564 et 852 et H. JEDIN, Tridentina im Carranzaprocess, dans Annuarium historiae conciliorum, 9, 1977, p. 180-189; G. Manzoni éd., Estratto del processo di Pietro Carnesecchi, dans Miscellanea di storia italiana, 10, 1870, p. 514-516.

${ }^{57}$ Voir R. Ancel, Paul IV et le concile, dans Revue d'histoire ecclésiastique, 8, 1907, p. 716-741. 
tout de même subi un long procès devant l'Inquisition sous Paul IV ${ }^{58}$. Son successeur à Modène, Egidio Foscarari, a lui aussi connu les prisons de l'Inquisition romaine sous ce même pape. Or, c'est entre autres à lui que les légats confient le soin d'instruire le procès des hérétiques repentants venant au concile. Le Saint-Office peut donc croire que les légats et les pères conciliaires conservent quelques coupables sympathies pour les idées hétérodoxes et que leur indulgence vis à vis des hérétiques repentis risque d'être préjudiciable à la cause catholique. Certes, cette méfiance ne se manifeste pas de façon ouverte dès le début : Gaspar Fantino, qui avait échappé à l'inquisiteur de Faenza, est jugé à Trente sans protestation de l'Inquisition romaine par l'évêque de Modène en avril 1562. Il semble bien que le durcissement du SaintOffice vis à vis de ce qu'il considère comme des empiétements sur sa juridiction date de la fin de l'année 1562 alors qu'une forte minorité de pères conciliaires italiens s'allient avec les «Oltramontani» pour s'opposer à la curie et exiger des réformes. La méfiance du Saint-Office devient alors hostilité.

Si Pie IV et Charles Borromée ne partagent pas complètement cette hostilité, ils sont loin de soutenir le concile face à l'Inquisition. La crainte du conciliarisme suffit pour expliquer cette attitude : le concile de Trente ne doit pas devenir comme à Bâle un organe indépendant de gouvernement de l'Église. Mais le pape et son neveu désapprouvent aussi l'indulgence des pères conciliaires. Le pontificat de Pie IV est trop souvent présenté comme une parenthèse «libérale» entre les règnes des rigoureux Paul IV et Pie V. Mais si Pie IV rompt avec le régime de terreur du pape Carafa, il n'a pas l'intention d'entraver la lutte contre l'hérésie. La situation catastrophique du catholicisme en France et les risques de contagion en Italie inquiètent la curie. Les massacres des Vaudois de Calabre et des Pouilles, pendant le pontificat de Pie IV, doivent suffire à retirer à ce pape sa réputation d'indulgence. Pas plus que Borromée, il n'est prêt à renoncer à la répression pour laisser le concile absoudre tous les pénitents. Borromée est très clair sur ce point et il écrit à Morone : "Comme votre Seigneurie Illustrissime le dit, l'Inquisition est bonne et sainte et comme telle, nous devons désirer qu'elle soit installée en tout lieu ${ }^{59}$. On peut sourire de voir Morone vanter une

${ }^{58}$ Sur le cardinal Morone et son procès, voir le recueil des articles publiés par l'éditeur des actes du procès, M. FIRpo, Inquisizione romana e Controriforma. Studi sul cardinal Giovanni Morone e il suo processo d'eresia, Bologne, 1992, 399 p.

59 "L'Inquisitione, come V. S ria Illma dice, e buona et santa, et come tale havemo da desiderar che sia posto in ogni luogo", J. Susta éd., op. cit., 4, p. 195. 
institution qui lui a valu de se retrouver en prison pour procès d'hérésie, mais il n'en reste pas moins que toute la correspondance de Borromée avec les légats sur la question des «inquisiti" est émaillée d'hommages appuyés au Saint-Office. En aucun cas, Pie IV et son neveu ne souhaitent que le concile prive l'Inquisition romaine d'une partie de son pouvoir.

À l'inverse, les légats et nombre de pères conciliaires sont aussi méfiants vis à vis de l'institution inquisitoriale que celle-ci l'est à leur égard. Un débat révélateur est celui de l'introduction de l'Inquisition sur le mode espagnol dans les domaines italiens de Philippe II. Si en 1547 les Napolitains n'ont pas eu l'idée d'aller se plaindre au concile du projet d'établir une Inquisition de type espagnol dans leur royaume, les Milanais, menacés par le même danger en 1563, envoient une députation à Trente pour obtenir le soutien du concile ${ }^{60}$. L'envoyé milanais Sforza Brivio obtient le soutien de tous les prélats concernés, qu'ils aient leur évêché en Lombardie ou qu'ils soient d'origine lombarde. Les prélats concernés ont le sentiment que le pape les abandonne et menacent de s'aligner totalement sur les positions espagnoles au concile ${ }^{61}$. Même le légat Simonetta, le plus proche sans doute des thèses curiales, manifeste ses craintes devant un tel projet ${ }^{62}$. Borromée doit écrire plusieurs fois aux légats pour les assurer que l'Inquisition milanaise n'aura rien à voir avec

${ }^{60}$ Sur l'essai d'introduction de l'Inquisition espagnole à Milan, voir E. VERGA, $I l$ municipio di Milano e l'Inquisizione di Spagna, 1563, dans Archivio storico lombardo, $3^{\text {e }}$ série, 8, 1897, p. 86-127 et L. FumI, L'Inquisizione romana e lo Stato di Milano, dans Archivio storico lombardo, 4e série, 13, 1910, p. 380 sq. Sur la question de l'Inquisition dans les possessions espagnoles, voir A. Borromeo, Contributo allo studio dell'Inquisizione e dei suoi rapporti con il potere episcopale nell'Italia del Cinquecento, dans Annuario dell'Istituto storico italiano per l'età moderna e contemporanea, 29-30, 1977-78, p. 219-276.

${ }^{61}$ Les légats préviennent ainsi Borromée dans une lettre du 19 aoât 1563 : «Per dir il vero la concessione fatta al re di Spagna dell'inquisitione di Milano ha posto molti prelati sudditi di S. $\mathbf{M}^{\text {ta }}$ in gran timore, et alcuni delli primi hanno detto a me Morone che nella reformatione de principi anderanno circonspetti a dir gli aggravii loro per non offender il re, perchè veggono che $S$. $M^{\text {ta }}$ impetra ogni cosa che vuole et ch'essi poi rimarriano abandonati della sede apostolica in man sua", J. Susta éd., op. cit., 4, p. 190.

${ }^{62}$ Dans sa réponse à Simonetta du 3 novembre 1563, Borromée assure le légat que l'on prendra en compte les avertissements qu'il donne et que le pape demeure très circonspect, ASV, Concilio 51, fol. 140. 
son homologue espagnole ${ }^{63}$. Le projet est enterré devant le concert de protestations en novembre $1563^{64}$.

Les pères conciliaires italiens n'éprouvent certes pas les mêmes craintes à l'égard de l'Inquisition romaine, ou tout du moins ils ne les montrent pas aussi clairement. Mais le souci des prélats tridentins de redonner à l'évêque tous ses pouvoirs dans son diocèse les rend hostiles, au moins par principe, à la présence d'un tribunal ne relevant pas du pouvoir épiscopal. L'un des derniers débats du concile montre bien ces réticences. Le 5 septembre 1563, vingt et un canons de réforme sont proposés aux pères conciliaires. Le cinquième porte sur le jugement des évêques ${ }^{65}$. Lors du débat, de nombreux pères conciliaires demandent l'ajout d'une clause interdisant le jugement d'un des sujets de l'évêque sans sa présence ou celle de son vicaire ${ }^{66}$. Certains autres s'opposent à tout jugement des évêques par l'Inquisition romaine, ce qui n'a rien d'étonnant pour les prélats de l'Église gallicane $^{67}$, mais qui l'est plus pour les évêques italiens ${ }^{68}$. La demande des

${ }^{63}$ Voir par exemple ASV, Concilio 51, fol. 131, $131 \mathrm{v}^{\circ}, 134 \mathrm{v}^{\circ}$ et 140 , lettres de Borromée à Simonetta, Rome, 21 et 25 août, 18 septembre et 3 novembre 1563. Borromée affirme dans ces lettres que Pie IV n'a pu refuser l'instauration de l'Inquisition «in questi tempi pericolosi», mais que cette Inquisition dépendra de Rome et non de l'Espagne, et qu'elle ne portera pas atteinte aux droits de l'ordinaire. Mais l'émotion des prélats italiens sujets de Philippe II pousse treize d'entre eux à faire une pétition auprès du pape. Après cette pétition, Borromée écrit aux légats le 28 août 1563 : «E dispiacciuto assai a S. B ${ }^{\text {nc }}$ che li prelati italiani subditi a S. M ${ }^{\text {ta }}$ Cath $^{\text {ca }}$ si siano intidimiditi per conto di questo rumore che va in volta de l'inquisitione di Milano, essendo che detta inquisitione se si concederà, sarà conveniente al jus commune, non preiudicherà a gli ordinarii et dependera da $S$. $S^{\text {ta }}$ et non dal'inquisitione di Spagna, et così m'ha detto N. Sre ch'io le scriva", J. Susta éd., op. cit., 4, p. 422.

${ }^{64}$ E. Verga, op. cit., p. 110. Mais la bulle instituant une Inquisition «à l'espagnole" à Milan était déjà prête. Elle est éditée dans E. Verga éd., op. cit., p. 119-126.

${ }^{65}$ Texte dans CT IX, p. 751

${ }^{60}$ Le premier à faire cette demande est le patriarche de Jérusalem qui souhaite le 11 septembre qu'on ajoute au cinquième canon "quod inquisitores non possint procedere contra subditos episcoporum absque episcopis aut eorum vicariis", CT IX, p. 798. Son avis est notamment repris par les évêques de Marsico le 16 septembre (CT IX, p. 823), de Chiron en Crète le 18 septembre (CT IX, p. 831), de Sebenico le 23 (CT IX, p. 850), de Chiusi le 24 (CT IX, p. 857).

${ }^{67}$ Nicolas de Pellevé, archevêque de Sens, s'oppose ainsi le 15 septembre à un jugement de l'évêque par les inquisiteurs, CT IX, p. 817.

${ }^{68}$ Le patriarche de Venise est le premier à demander, le 11 septembre 1563, à ce que seuls les canons du concile de Latran IV soient appliqués en cas de procès contre un évêque (CT IX, p. 798). Il est suivi par d'autres pères conciliaires, comme l'archevêque de Corcyre (CT IX, p. 813) ou l'évêque de Pienza (CT IX, p. 821). L'évêque de 
ambassadeurs portugais d'ajouter au septième canon, qui traite de l'absolution par les évêques, une exception pour les pays d'Inquisition est finalement rejetée ${ }^{69}$. Si le concile n'a pas traité de l'Inquisition, c'est aussi en raison de sa méfiance à l'égard de cette institution et de sa volonté d'affirmer le pouvoir des évêques contre toute juridiction extérieure.

L'incompréhension et la méfiance ont caractérisé les relations entre le concile de Trente et l'Inquisition romaine. Ces relations difficiles s'expliquent aussi par une approche différente de la réconciliation des hérétiques. Les deux procès en matière de foi faits au concile que nous avons conservé le prouvent. Ils n'ont rien à voir avec un procès d'inquisition normal. Ils sont beaucoup moins longs et les juges se préoccupent moins d'approfondir les opinions hérétiques de l'accusé. Leur indulgence semble bien plus grande, alors même que les deux «inquisiti» qui viennent demander leur réconciliation avouent de véritables hérésies, bien plus graves que d'avoir lu un livre mis à l'Index.

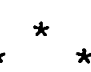

Les deux procès, distants d'une année, sont de nature très différente. Le premier, en avril 1562, est très vite expédié : seul Egidio Foscarari, l'évêque de Modène, mène l'interrogatoire, en une seule et très courte séance. Le second procès, en mars 1563, est conduit par une véritable commission de quatre prélats, dont Foscarari. L'interrogatoire est beaucoup plus complet. Seul lien entre ces deux procès, l'évêque de Modène semble être devenu l'expert du concile en réconciliation d'hérétiques. Les légats pouvaient difficilement choisir une personne ayant moins le comportement d'un inquisiteur, tel que le voyaient et le souhaitaient les cardinaux de la congrégation du Saint-Office. Dominicain bolonais à la science réputée, Foscarari, successeur de Morone à Modène en 1550, fait partie de la seconde génération des évêques réformateurs, qui a pâti comme la première du pontificat de Paul IV. Soupçonné tout comme Morone et les autres spirituali d'avoir des opinions hérétiques, Foscarari est emprisonné en 1558. Sa mansuétude à l'égard des cercles hétérodoxes de Modène, sa répugnance à utiliser l'appareil inquisitorial pour réprimer

Cività Castellana, Costantino Bonelli, va plus loin en demandant le 16 septembre : "Tollatur inquisitorum rigorositas", CT IX, p. 822.

${ }^{69}$ CT IX, p. 891. Le cardinal de Lorraine, dans le vote final, demande le premier le retrait de cette clause d'exception, CT IX, p. 989. 
l'hérésie lui sont certainement alors reprochées ${ }^{70}$. Mais son absolue orthodoxie est prouvée et il est comme Morone blanchi par Pie IV. Il n'en reste pas moins un des plus vigoureux défenseur de la réforme à Trente, n'hésitant pas à s'opposer à la curie en appuyant les demandes des «Oltramontani».

C'est pourtant à lui que les légats confient la tâche d'instruire le procès de Gaspar Fantino, du diocèse de Faenza ${ }^{71}$. Le 11 octobre 1561, Foscarari avait reçu délégation du pouvoir de réconcilier des hérétiques, conféré aux légats par le bref du pape du 8 août $1561^{72}$. Quand Fantino vient demander sa réconciliation, Foscarari accepte de le juger, sans que le fait qu'il ait déjà été condamné par l'inquisiteur de Faenza, terre pontificale, ne semble guère le gêner vis à vis de l'Inquisition romaine. L'interrogatoire est d'ailleurs très court, puisqu'il se déroule en une séance seulement, le 21 avril 1562, dans la maison de l'archevêque de Lanciano. Fantino avait été jugé par l'Inquisition de Faenza douze ans auparavant. Condamné à la prison à vie, il réussit à s'enfuir ce qui lui vaut une seconde condamnation par contumace comme relaps ${ }^{73}$. La première question de l'évêque de Modène concerne les raisons de sa condamnation. Gaspar Fantino explique qu'il pensait «que le pape n'avait aucun pouvoir, que l'âme était mortelle et que dans la sainte hostie ne se trouvait pas le vrai corps du Christ réellement et essentiellement, mais seulement la grâce ${ }^{74}$. Foscarari lui demande s'il croyait encore à cela lors de son abjuration et Fantino, prudent, répond

${ }^{70}$ Sur l'action de Foscarari à Modène, voir M. FIRPo, Riforma protestante..., op. cit., p. 64-66. Silvana Seidel Menchi situe l'évêque de Modène parmi les défenseurs d'Érasme, en précisant : "L'interesse del Foscarari per Erasmo doveva essere di natura pastorale», S. SeIdel MenchI, Erasmo in Italia 1520-1580, Turin, 1987, p. 238. Son propre vicaire, Fra Domenico da Imola, décrit en 1575, soit plus de dix ans après la mort de Foscarari, à l'inquisiteur de Modène Eliseo Capis, la conduite qu'en accord avec Jules III, Foscarari avait adoptée dans son diocèse, qui ressemble singulièrement à celle qu'il a comme juge au concile : "Julio III f. m. fece il Vescovo papa di Modena, con aspettarli tutti a penitenza, chi in voce sola senza scritto, chi con testimonio, chi senza : purche tornassero, si accettavano tutti come appare nel breve suo", Modène, Archivio di Stato, Inquisizione, busta 149, cité par A. Rotondo, Attegiamenti della vita morale italiana del Cinquecento : la pratica nicodemitica, dans Rivista storica italiana, 79, 1967, p. 1026, n. 122.

${ }^{71}$ L'acte notarié de l'interrogatoire et de l'abjuration, rédigé par le notaire Antonio Peregrini, se trouve dans ASV, Concilio 72, fol. 154 sq. Fantino est indifféremment appelé «Fantinus» ou "De Fantis» dans l'acte, mais lui-même signe «Fantinus».

${ }^{72}$ Le bref de Pie IV et la délégation de pouvoir par les légats à Foscarari sont cités intégralement dans les actes du procès, ASV, Concilio 72, fol. 156-159.

${ }^{73}$ ASV, Concilio 72, fol. 154.

74 "Quod papa nullam habebat facultatem, quod anima erat mortalis et quod in 
que non. Pourquoi a-t-il fui alors? Le pénitent explique que c'est par crainte de la sévérité de l'Inquisition romaine qu'il s'est échappé, sans aucune aide extérieure. Cette peur se conjugue avec sa répugnance non devant les châtiments eux-mêmes, mais devant leur ignominie : Fantino n'a pas supporté de devoir venir corde au cou à la porte de la cathédrale, de devoir faire une abjuration publique alors qu'il avait déjà abjuré en privé. On retrouve ici le thème bien connu des historiens de l'Inquisition, que cette institution ne régnait pas tant par la terreur des châtiments euxmêmes que par la publicité infamante donnée à la condamnation. Après son évasion, Fantino raconte qu'il s'est d'abord engagé dans l'armée vénitienne, qu'il a fait toutes les guerres qui se sont déroulées en Italie et qu'il était aussi en Picardie, sans doute comme mercenaire des armées espagnoles lors des dernières campagnes avant la paix du Cateau-Cambrésis ${ }^{75}$. Il assure l'évêque de Modène qu'il n'a jamais reparlé de ses croyances hétérodoxes avec qui que ce soit. Certes, il doit reconnaître qu'il n'a pas toujours respecté le jeûne, mais il s'en excuse en arguant des contraintes de la vie militaire.

Ce court interrogatoire ne nous donne pas beaucoup de renseignements sur ce mercenaire sans doute mis au chômage par la paix de 1559 et qui voudrait tirer un trait sur son passé. Son hérésie est en quelque sorte banale : gibeline, pomponazzienne et sacramentaire. Certes, la conjonction de ces trois opinions rend l'homme un peu plus original. Il a pu être influencé par le milieu hérétique très actif de Faenza ${ }^{76}$. Sa condamnation a lieu la même année que l'exécution de Fanino Fanini, boulanger devenu le prédicateur de la Réforme en Émilie-Romagne. Fantino peut avoir subi son influence, notamment sur le dogme eucharistique, mais il a trouvé ailleurs la négation de l'immortalité de l'âme. A-t-il réellement subi l'influence de l'averroïsme ou plus exactement de l'aristotélisme matérialiste enseigné par Pomponazzi à Padoue au début du siècle? Certes, Fantino est cultivé. Il est par exemple capable de souscrire en latin à son acte d'abjuration. Mais nous n'avons affaire ni à un théologien, ni à un convaincu. Dans quelle mesure est-il sincère quand il dit avoir cessé de croire en ces opinions dès

hostia sacra non consistebat verum corpus Christi realiter et essentialiter, sed tantummodo gratia», ASV, Concilio 72, fol. $154 \mathrm{v}^{\circ}$.

75 "Deinde in omnibus bellis que fuerunt in Italia semper interfuit et etiam in bello ultimo facto in Picardia», Ibid., fol. $154 v^{\circ}$.

${ }^{76}$ Sur Faenza, centre de diffusion de la Réforme, et sur la répression inquisitoriale, voir F. LANzONI, La Controriforma nella città e diocesi di Faenza, Faenza, 1925, 315 p. et S. Caponetro, op. cit., p. 279 sq. 
avant son abjuration? Il ne s'est pas enfui à Genève ou à Bâle, preuve peutêtre que son hétérodoxie reste une affaire personnelle, voire simplement des propos lancés sans y penser dans une discussion. L'Inquisition, en le condamnant, l'a marginalisé et Fantino après douze années dans différentes armées aspire à retrouver la normalité sociale. Il a eu l'intelligence de venir au concile pour obtenir une réconciliation à bon compte. Après son court interrogatoire et l'examen des pièces de son procès à Faenza, Foscarari lui fait prononcer le 28 avril une abjuration, qui ne porte que sur ses trois opinions hérétiques, dans la maison de l'archevêque de Lanciano, donc un lieu privé. Il lui lit après la sentence de réconciliation, qui l'oblige à ne pas chercher à se venger de ceux qui l'ont dénoncé, de se soumettre aux pénitences que lui imposera l'inquisiteur de Faenza et de renouveler son abjuration à Faenza dans un lieu privé. L'abjuration s'accompagne du chant du psaume Miserere mei Deum repris par toute l'assistance.

La rapidité du procès, la faiblesse de la peine pour un hérétique relaps sont autant d'éléments qui surprennent. Dans sa sentence, Foscarari insiste plus sur la miséricorde que sur la pénitence. Du rapide interrogatoire qu'il a mené, il a tiré la conclusion que l'homme n'était pas dangereux. Sa fuite procède plus de la honte du châtiment que d'opinions hérétiques. L'évêque de Modène le comprend si bien qu'il ne lui impose une abjuration publique ni à Trente, ni à Faenza. Il conçoit son rôle de juge plus comme celui d'un confesseur que d'un inquisiteur.

Cette logique s'applique aussi, malgré toutes les différences, dans le procès d'Agostino Centurione, ce marchand génois passé au calvinisme en France, qui vient demander sa réconciliation en janvier 1563. Cette fois, les formes sont mieux respectées et quatre prélats, dont trois issus de la famille dominicaine, interrogent longuement Centurione le 30 mars et le 5 avril $1563^{77}$. Sans doute, les difficultés avec l'Inquisition romaine expliquent ce plus grand sérieux de l'interrogatoire, que, comme pour Fantino, un notaire prend en note. Comme dans le cas de Fantino, Centurione s'est présenté de lui-même. Il insiste d'ailleurs sur ce point, déclarant qu'il aurait pu rester en toute sécurité en France, sa seconde patrie où il vit depuis l'enfance. Il est interrogé dans la maison de l'archevêque de Gênes. Centurione a su préparer son procès et arrive avec une sorte de déclaration d'intention écrite, qui n'est pas consignée dans les actes. Mais il y déclare qu'il est venu à Trente plutôt qu'à Rome parce qu'au concile se trouvent des hommes doctes. Les juges l'interrogent sur ce point et Centurione répond

${ }^{77}$ Le procès, dont l'original se trouve à l'Archivio Segreto Vaticano, Concilio 12, fol. 131-145, est édité par L. Carcereri, Agostino Centurione, op. cit., p. 79-99. 
qu'il a bien fait écrire à Rome par une de ses relations, mais qu'il a préféré venir au concile, où sont rassemblés tant de théologiens ${ }^{78}$. Quand on lui demande pourquoi il ne s'est pas non plus rendu auprès de l'inquisiteur de Gênes, qui l'avait cité à comparaître, il répond que c'est pour la même raison que celle qui lui a fait préférer Trente à Rome. Il ajoute cependant que l'inquisiteur pouvait faire justice, mais non grâce, alors que le concile pouvait faire les deux ${ }^{79}$.

Cet essai peu convaincant d'expliquer pourquoi il a préféré éviter l'Inquisition romaine et a choisi le jugement plus indulgent du concile ne doit pas cependant nous faire négliger l'importance du témoignage. Centurione est issu d'une famille importante à Gênes comme à Lyon ${ }^{80}$. Il est cultivé, intelligent, capable d'analyser sa propre évolution religieuse. La mansuétude du tribunal qu'il a lui-même choisi lui permet peut-être une plus grande liberté de parole. Italien, il a été "contaminé» par les idées réformées en France, situation que comprennent ses juges parce qu'ils la redoutent. Depuis les succès de la Réforme en France, les autorités ecclésiastiques italiennes craignent que les nombreux Italiens qui résident en France ne deviennent huguenots et cherchent à introduire le calvinisme en Italie. La République de Gênes, si l'on en croit une lettre de Foscarari au cardinal Morone du 23 mars 1562, a déjà essayé, mais en vain, de faire rapatrier tous les Génois vivant en France ${ }^{81}$. Le cardinal Borromée au

${ }^{78}$ «Interrogatus an Romae scripserit vel scribi jusserit, ut Ecclesiae reconciliaretur, et si hoc fecit, cur dicit in sua confessione, propterea se venisse ad Concilium et non ivisse Romam, quia sciebat in Concilio esse viros doctos, qui eum docerent. Respondit : io non ho scritto a Roma per questo conto, ma essendomi offerto da messer Gio. Batta Prementorio Giordano l'opera, di fare che sua sorella scriverebbe alla moglie di messer Donato Mattheo Minali Thesoriere di S. $S^{\text {tà }}$ perchè vedesse in che forma mi possea riconciliare, mi son contentato che si scrivesse, ma con tutto questo mi partei, et venni a Trento senza aspettare risposta. Interrogatus, an dubitaret Romae deesse theologos, qui possent eum docere et instruere? Respondit : io non dubitava che ci fussero, ma che qui in Concilio ci fusse miglior commodità, essendoci concorsa da ogni banda gran qualità di theologi», L. CARCERERI, op. cit., p. 81.

79 «Sapeva, ch'il Padre Inquisitore poteva fare giustitia ma non gratia, et io bramava d'andare in loco dove potesse anco haver gratia insieme con la giustitia". Centurione ajoute qu'il a craint "le molestie ch'havrei possute patire dagli creditori» ce qui fait naître quelques soupçons sur l'état de ses affaires, ibid., p. 84.

${ }^{80}$ Les Centurioni comptaient en 1545 parmi les plus riches marchands lyonnais. Rafaele Centurione avait acquis des lettres de naturalisation, R. GAscon, Grand commerce et vie urbaine au XVI siècle. Lyon et ses marchands (environs de 1520environs de 1580), Paris, 1971, p. 411.

${ }^{81}$ ASV, Concilio 42, fol. 246 vo-247, "Mons ${ }^{r}$ Arcivescovo di Genoa ha lettere dalla città sua, che havendo ella comandato ad alcuni de suoi cittadini che sono in 
même moment écrit au nonce en France de se renseigner sur les Italiens séduits par l'hérésie ${ }^{82}$.

Or, de toutes les communautés italiennes, celle de Lyon est sans doute la plus touchée par la Réforme ${ }^{83}$. Les marchands florentins, milanais, génois, lucquois ou piémontais sont en contact permanent avec leurs collègues français gagnés aux idées nouvelles. Ils doivent parfois aller à Genève pour faire leur commerce et ils y retrouvent l'importante communauté des exilés italiens ${ }^{84}$. Agostino Centurione, installé à Lyon depuis 1542, fait partie intégrante de ce monde de marchands dont le mode de vie n'est guère conforme aux exigences de l'Église. Il explique ainsi que les marchands italiens à Lyon n'ont pas l'habitude de respecter le Carême «en raison de l'air insalubre ${ }^{85}$, même s'il assure ses juges qu'il a fait maigre le vendredi et le samedi quand il n'était pas malade. L'anticléricalisme joue aussi un grand rôle pour attirer les marchands italiens à la Réforme. Centurione émaille son interrogatoire de propos méprisants sur la cupidité des prêtres, qui les a poussés à inventer le Purgatoire et l'intercession des saints, sur la vie pure des ministres par comparaison avec celle de leurs adversaires. Il raconte même qu'une fois, il a vu un prêtre refuser de dire la messe s'il n'était pas payé pour le faire. Cet épisode semble l'avoir beau-

Francia che se ne tornassero a Genoa per lo pericolo della infettione della heresia di quel Regno, che essi sono ricorsi al Re di Navarra, il quale ha scritto lettere minazzevoli a Genoesi». Les juges de Centurione lui demandent d'ailleurs pendant son procès s'il faisait partie de la délégation génoise auprès de la cour. Centurione nie d'abord, puis s'explique par un long mémoire, joint aux actes du procès et perdu depuis, L. CARCERERI, op. cit., p. 84.

${ }^{82}$ ASV, Nunziature diverse 274/2, fol. 489, "La diligenza che V. S. usarà in pigliar informatione degl'Italiani che in quel Regno sono poco Cattolici sara gratissima a S. San ${ }^{\text {tà }}$, lettre du 16 mars 1562.

${ }^{83}$ Le cas de Centurione et d'autres exemples permettent d'infirmer l'allégation d'Henri Hours décrivant la montée de la Réforme à Lyon : "A l'exception des nations italiennes, tous les milieux de Lyon étaient touchés, en si grand nombre (la moitié de la population, peut-être) qu'on sentait venir le jour où le consulat lui-même tomberait aux mains des protestants", J. Gadille dir., Le diocèse de Lyon, Paris, 1983, p. 126 (Histoire des diocèses de France, 16). Sur la communauté réformée italienne à Lyon et ses rapports parfois difficiles avec Genève, voir H. MEYLAN, Bèze et les Italiens de Lyon, dans Bibliothèque d'humanisme et Renaissance, 14, 1952, p. 235-249. Sur le rôle de Lyon dans l'introduction du calvinisme en Italie et particulièrement à Gênes, voir S. CAPONETTO, op. cit., p. 377-8.

${ }^{84}$ Voir E. W. Monter, The Italians in Geneva 1550-1600, dans L. Monnier éd., Genève et l'Italie, Genève, 1969, p. 53-77. La croissance de la communauté italienne à Genève est très importante jusqu'en 1569.

${ }^{85}$ «Per l'opinione dell'aere insalubre», L. CARCERERI, op. cit., p. 94. 
coup choqué ${ }^{86}$. Le mode de vie du marchand, son anticléricalisme traditionnel, son insertion dans un milieu lyonnais largement gagné aux idées nouvelles le prédisposent à adhérer à la Réforme ${ }^{87}$.

Mais cette adhésion ne semble pas pleine et entière et subsistent des lambeaux de son ancienne pratique. Il va encore de temps à autre à la messe, ce qui lui vaut d'être repris par un huguenot français, mais il cesse de se confesser et de communier. Il assiste à trois cènes protestantes, mais sans lui-même communier ${ }^{88}$. Il accepte devant ces juges de dater sa conversion, au printemps de l'année $1561^{89}$. Mais il affirme avoir eu des doutes et un combat en sa propre conscience entre l'ancienne et la nouvelle foi ${ }^{90}$. Est-ce une simple ruse pour adoucir ses juges? On peut le croire en voyant les lectures de Centurione, qui ne sont pas précisément à l'image du marchand un peu simplet qu'il veut donner de lui. Il possède un Nouveau Testament commenté par Calvin, une Confession de foi (sans doute celle du synode de Paris de 1559, mais que Centurione, de façon faussement naïve, décrit évasivement comme huguenote ou luthérienne), livres qu'il avait avec lui lors de son séjour à Gênes, l'Institution de la religion chrétienne et de nombreux sermons de Calvin ${ }^{91}$. Centurione s'est certainement beaucoup plus engagé dans sa nouvelle foi qu'il ne veut bien le dire. Il avoue d'ailleurs que les opinions des ministres calvinistes lui semblaient alors mieux fon-

so Ibid., p. 82.

${ }^{87}$ John Tedeschi, mentionnant en passant le cas de Centurione, souligne "the unwitting erosion worked on his Catholic beliefs and practices by the many years he spent in a milieu where Catholicism and Calvinism enjoyed an uneasy coexistence", J. TEDESCHI, op. cit., p. 33. Je pense cependant que cette érosion est d'abord dûe au mode de vie des marchands, mais que la coexistence avec les calvinistes la transforme en un choix confessionnel.

${ }^{88}$ L. CARCERERI, op. cit., p. 83.

${ }^{89}$ C'est aussi l'époque où il cesse de se confesser et de communier, ibid, p. 83 et 89.

${ }^{90}$ À propos des ministres, Centurione dit : «Non gli ho creduto assolutamente per esser nodrito in doctrina et fede al tutto contraria a quella, onde nell'animo mio combattevano e le ragioni di quei ministri, alle quali non gli sapeva rispondere, et dall'altra parte l'essere allevato nelle contrarie sententie, alla qual fede io non sapeva rendere ragioni ", ibid., p. 82.

${ }^{91}$ Centurione mentionne aussi d'autres livres : "L'Armonia sopra gli Evangelii, il Baston della fede, il Brocchiero della fede, molte prediche del Calvino o altri, et molti altri [libri] de quali non mi ricordo gli nomi», Idid., p. 89. Sur la grande et précoce influence de l'Institution de la religion chrétienne et des écrits de Calvin en général sur le milieu hérétique italien, voir U. Rozzo et S. Seidel MENCHI, Livre et Réforme en Italie, dans J.-F. Gilmont éd., La Réforme et le livre. L'Europe de l'imprimé (1517- v. 1570), Paris, 1990, p. 351. 
dées sur l'Écriture ${ }^{92}$. Après le coup de main huguenot qui assure aux protestants le contrôle de la ville dans la nuit du. 30 avril 1562 , il a monté «je ne sais quelle garde ${ }^{93}$. Même ainsi minimisée, sa participation à l'insurrection huguenote peut lui coûter cher, comme son séjour de deux mois à Genève, qu'il essaye de justifier par des raisons commerciales ${ }^{94}$. Mais ses juges s'intéressent peu au fait de savoir s'il a réellement cru aux nouvelles idées. Leur interrogatoire porte surtout sur deux points : sa pratique religieuse et les Italiens qui, à Gênes, Lyon ou Genève, ont eux aussi adhéré au calvinisme.

Les prélats veulent savoir si Centurione, après sa conversion, a continué à prier. Il répond qu'il a continué à dire le Notre Père et «quelque autre prière, suivant la nécessité que j'avais de demander quelque chose à Dieu "95. Par contre, il cesse de dire l'Ave Maria, qu'il ne recommence à réciter que depuis qu'il est à Trente. À la demande des juges, il fournit la preuve qu'il le connaît bien par cœur. Il a aussi l'habitude de réciter en vulgaire les sept psaumes de la pénitence, qu'il récitait en latin à Gênes ${ }^{96}$. Vérité ou ruse, il assure qu'il n'a pas profané l'hostie en communiant sans s'être confessé de ses opinions hérétiques ou en participant à la cène réformée. Les quatre juges ne cherchent pas à en savoir plus. Ils sont plus intéressés par les noms des autres Italiens hérétiques que Centurione a pu croiser.

Centurione nie avoir fait une quelconque œuvre de propagande. Il admet avoir défendu la moralité des ministres, quand celle-ci était attaquée, en affirmant qu'ils étaient des hommes de bien, et avoir essayé d'emmener au prêche un de ses compatriotes qui s'y est refusé ${ }^{97}$. Les Italiens hérétiques qu'il a fréquentés n'ont donc pas été convertis par ses soins. Aux questions répétées des juges sur l'identité de ces hérétiques, Centurione oppose prudemment des réponses évasives ou affirme ne plus très bien se souvenir. Mais au cours de son interrogatoire, il livre tout de même une trentaine de noms, dont celui de son propre frère Battista. Toutes ces personnes, rencontrées à Lyon ou Genève, sont génoises, lucquoises ou piémontaises. La plupart sont des marchands. Sur l'activité des réformés en

${ }^{92}$ "Io inclinava più alla sententia delli ministri, induttoci dell'authorità della scriturra, che loro allegavano", ibid., p. 93.

${ }_{93}$ "È ben vero che facendosi une certa grida fu bisogno, che per doi giorni io portassi l'arme, et facessi non sò che guardia", ibid., p. 87.

${ }^{94}$ Ibid., p. 87-8.

95 « Io diceva il Pater nostro, et poi qualche altra preghiera secondo la necessità, che mi occorreva di dimandare a Dio qualche cosa», ibid., p. 93.

${ }^{96}$ Ibid., p. 93-4.

${ }^{97}$ Ibid., p. 83 et 86. 
Italie même, Centurione est beaucoup moins précis. Il nie toute conjuration organisée de l'étranger. Malgré les instances pressantes des archevêques de Gênes et de Lanciano, il se contente de rapporter des rumeurs : il paraît que les Génois réformés de Lyon ont envoyé un ministre en Ligurie; il paraît qu'à Gênes même, ce ministre aurait célébré une cène, avec les calvinistes, qui, paraît-il, résident dans la ville ${ }^{98}$.

Toutes ces assertions extrêmement vagues deviennent beaucoup plus précises quand il s'agit de l'action de Centurione lui-même lors de ses séjours à Gênes. Il y est retourné deux fois après sa conversion. La première fois, en août ou septembre 1561, il a avec lui un Nouveau Testament commenté par Calvin et une confession de foi, qu'il n'a montré qu'à une personne, Giovanni Battista Giordano, lequel a poussé les hauts cris en disant que c'étaient des livres interdits et qu'il fallait qu'il les jette. Centurione a par ailleurs avoué à son beau-père, Giovanni Pallavicino, chez qui il demeure, une certaine sympathie pour les idées réformées, tout en affirmant devant les protestations de Pallavicino qu'il est resté catholique ${ }^{99}$. A son second séjour, juste avant de se rendre à Trente, c'est Giordano qui le convainc d'abord de faire écrire à Rome, puis de se rendre au concile pour obtenir sa réconciliation ${ }^{100}$. Lyon et Genève sont les seuls lieux où il a rencontré des hérétiques, alors que Gênes apparaît comme l'endroit où l'on a tout fait pour le faire revenir au catholicisme. S'agit-il de la réalité ou de la simple volonté de protéger des personnes que l'Inquisition peut atteindre? Il est impossible de se prononcer.

Les juges semblent cependant se contenter des aveux de Centurione, qui abjure le 5 avril 1563 dans l'église Saint-Laurent. La main sur les Évangiles, il fait une longue profession de foi catholique, qui contrairement à celle de Fantino, ne se limite pas aux hérésies avouées, mais embrasse tous les points controversés entre catholiques et protestants : Purgatoire, intercession des saints, mais aussi justification, transsubstantiation, infaillibilité de l'Église, pouvoir du pape, etc. Centurione promet aussi de ne plus lire de livres hérétiques et de dénoncer au Saint-Office toute personne hérétique de sa connaissance ${ }^{101}$. L'archevêque de Gênes, suivant le même cérémonial que pour Fantino, lui donne alors sa main à baiser et tous chantent le même psaume Miserere mei Deus. Les trois juges présents (Foscarari étant parti pour une brève visite à son diocèse) lui lisent alors leur sentence : après le rappel de la miséricorde de Dieu, ils l'absolvent et lui

${ }_{98}$ Ibid., p. 84-5 et $92-3$.

${ }^{99}$ Ibid., p. 89.

100 Ibid., p. 90.

${ }^{101}$ Ibid., p. 95-7. 
imposent une pénitence légère. Pendant un an, Centurione devra visiter chaque dimanche deux ou trois églises, y dire cinq Pater et cinq Ave et y faire des aumônes. Il devra faire célébrer chaque semaine une messe pour les défunts, à laquelle il assistera et après laquelle il prononcera à nouveau cinq Pater et cinq Ave. D’autres pratiques pieuses (jeûnes, vénération d'une image de saint, confession mensuelle) lui sont imposées. Il ne devra plus remettre les pieds à Lyon, sauf pour des raisons commerciales impératives et avec l'autorisation de l'archevêque ou de l'inquisiteur de Gênes ${ }^{102}$.

Comme dans le cas de Fantino, mais dans une moindre mesure, la peine semble bien légère et le procès un peu bâclé. Pourtant, les juges ont consulté cinq docteurs en théologie présents à Trente, dont le général des dominicains, qui ont approuvé leur sentence. L'aspect incomplet du procès vient aussi du fait qu'il nous manque les confessions écrites de Centurione : nous ne disposons que de la transcription par le notaire de ses aveux oraux. Mais il n'en reste pas moins l'impression que si Centurione a minimisé le plus possible la profondeur de sa conversion au calvinisme, ses juges n'ont pas cherché à le mettre en défaut dans leur interrogatoire et se sont presque toujours satisfaits de ses réponses. De nombreuses questions restent sans réponse : pourquoi Centurione revient-il en Italie? Sa femme et éventuellement ses enfants ont-ils suivi le chef de famille dans son expérience religieuse? Rien dans son interrogatoire ne permet de répondre. Sur la sincérité à la fois de la conversion de Centurione au calvinisme, puis de son repentir, on peut émettre quelques suppositions.

Centurione avoue à plusieurs reprises la satisfaction que lui procurent les prêches et les livres réformés. Cette satisfaction, dit-il, vient des prières et de la condamnation des vices que font les ministres ${ }^{103}$. Centurione avoue la séduction de la nouvelle liturgie réformée et de la nouvelle morale, exigeante certes, mais qui correspond à ses attentes religieuses. Il garde toujours un certain respect en parlant des ministres, surtout par comparaison avec les prêtres catholiques. Son anticléricalisme se masque à peine devant le tribunal du concile. Mais ce souci moral, cette admiration pour les mœurs des pasteurs n'ont pas suffi pour faire de lui un réformé. Son

${ }^{102}$ Ibid., p. 97-9.

${ }^{103}$ Pendant son séjour à Gênes chez son beau-père, "quelli di casa mi riprendevano, per essersi detto ch'io era de quelli ch'haveano queste opinioni, et io replica che non mi era partito dalla fede cattolica, ma ch'io n'havea sentito piacere, et lettone libri». Quand les juges lui demandent s'il croyait tout ce que disaient les ministres, il répond par la négative, mais ajoute : «È ben vero, ch'io haveva dilettatione con satisfattion delle cose dette dagli ministri per le preghiere et reprensioni, che facevano delli vitii, ibid., p. 89 et 93. 
silence sur la plupart des dogmes contestés par la Réforme est révélateur, même s'il a pu évoquer le sujet dans ses confessions écrites. Il dit lui-même à plusieurs reprises avoir toujours conservé des doutes devant les affirmations des ministres. Centurione, au vu de ses lectures, a une connaissance approfondie du dogme réformé. S'il retourne au catholicisme, ce n'est pas sans avoir discuté avec des théologiens à Trente des points qui le tracassent et, au moins d'après ses dires devant ses juges, avoir été convaincu ${ }^{104}$. Simulation pour obtenir à bon compte sa réconciliation? Démarche religieuse originale? Souci de pouvoir revenir dans son pays sans être inquiété, alors que l'activité commerciale lyonnaise est réduite à néant par la guerre civile? Toutes ces explications peuvent être valables et il est impossible de dire avec certitude quelle est la bonne.

Fantino, le mercenaire de Faenza, Centurione, le marchand génois, sans doute aussi Marchesi, le notaire de Bergame ont obtenu ainsi l'absolution pour leurs hérésies. D'autres dissidents italiens ont peut-être aussi cherché à se réconcilier avec l'Église à Trente, mais ils n'ont pas dû être très nombreux ${ }^{105}$. Les deux figures bien différentes que nous pouvons connaître confirment l'image contrastée de la dissidence religieuse en Italie. Fantino a une pensée hétérodoxe qui ne se laisse pas enfermer dans les dogmes d'une Église, quelle qu'elle soit. Centurione a été séduit par la valeur morale de l'enseignement réformé plus que par son dogme. L'un a adhéré sérieusement à une Église, l'autre a profité de sa carrière de soldat pour éviter tout choix. Tous les deux ont trouvé (recherché?) au concile un jugement plein de mansuétude.

Leurs juges ont ainsi respecté la volonté des légats d'accueillir favorablement tout hérétique repentant. Les deux interrogatoires que nous avons ont un certain nombre de points en commun : les juges ne s'appe-

${ }^{104}$ Quand on lui demande s'il croit désormais tout ce que l'Église enseigne, il répond : "Signor si, et se non fusse cosi non mi sarei fermato qui in Trento, nè farei questo atto presente, che fo, et con questa fede intendo vivere et morire», ibid., p. 83. Mais on peut aussi voir dans sa démarche une de ces «abiure consapevolmente nicodemitiche", que remarquait pour d'autres cas A. Rotondo, Atteggiamenti, op. cit., p. 1012.

${ }^{105}$ L'évêque de Lerida dit le 16 mars 1562 que l'archevêque de Gênes et les évêques de Crémone et Modène ont à Trente des fugitifs de leur diocèse qui veulent être réconciliés. Ces fugitifs n'ont laissé aucune trace dans les sources. Voir supra $n$. 34. On ne peut compter, comme le fait L. Carcereri, le dominicain fra Jacopo Paleologo da Chio, surnommé Mascellara, parmi les «inquisiti» jugés à Trente. Mascellara 
santissent pas sur les fautes du coupable. Ils cherchent surtout à savoir s'il a respecté le mode de vie catholique (jeûne, faire maigre, réciter ses prières, etc.). La dénonciation des complices ou des autres hérétiques n'est poursuivie que mollement : Fantino dit ne pas avoir eu d'aide dans son évasion, sans que son juge cherche à en savoir plus; Centurione dénonce seulement les hérétiques hors de la portée de l'Inquisition et reste silencieux sur ceux qui habiteraient Gênes. Ces interrogatoires très brefs ont certes été préparés : les juges ont en leurs possessions les dossiers des procès précédents et les confessions écrites des accusés. Mais la volonté de réconcilier est plus forte que celle d'enquêter, celle de confesser plus importante que celle de punir.

Doit-on réellement opposer cette volonté à la logique répressive de l'Inquisition? Les sentences insistent toutes deux sur la miséricorde, dans ce style ecclésiastico-administratif qui paraît de pure convenance. Si les dissidents étaient venus en foule obtenir leur réconciliation à Trente, les pères conciliaires auraient-ils conservé cette même attitude? On peut en douter et de toute façon, l'Inquisition romaine ne l'aurait pas tolérée. Fait plus avéré, les prélats de retour dans leur diocèse collaborent avec l'Inquisition romaine, sans que se posent les problèmes qui s'étaient posés à Trente. Miséricordieux au concile, les évêques deviennent répressifs dans leur diocèse ou au moins collaborent à la grande vague de répression des années 1566-1568 ${ }^{106}$.

Y a-t-il vraiment une contradiction? Il serait trop simple d'opposer radicalement concile et Inquisition. On y retrouve les mêmes hommes. Certes, ces hommes qui avant ou après le concile répriment sévérement l'hérésie dans leur diocèse se sont montrés beaucoup moins répressifs à Trente. Mais à partir du moment où l'Inquisition n'empiète pas sur leurs pouvoirs épiscopaux et qu'elle reste soumise à l'unique autorité du pape, les prélats italiens lui sont favorables ${ }^{107}$. Certes, pour des raisons à la fois

avait fui sa prison de Ripetta pour se réfugier en France, où il demande son absolution au légat Ippolito d'Este. Celui-ci le renvoie à son maître de l'Ordre, qui est au concile. Mascellara n'est donc pas jugé par le concile, mais par son supérieur, suivant une procédure classique, L. CARCERERI, Appunti.., op. cit., p. 74-75.

${ }^{106}$ Le cardinal Morone, qui a récupéré son évêché de Modène à la mort de Foscarari en 1564, laisse ainsi faire l'Inquisition qui démantèle à peu près tout le réseau hérétique dans sa ville. Voir C. BIANCo, La comunità di "fratelli" nel movimento ereticale modenese del'500, dans Rivista storica italiana, 92, 1980, p. 621-679.

${ }^{107}$ On le voit particulièrement bien dans l'affaire de l'Inquisition de Milan. Quand Rome déclare qu'elle n'aura rien à voir avec l'Inquisition espagnole, les légats peuvent écrire à Borromée la satisfaction des prélats italiens : «È stato molto a pro-

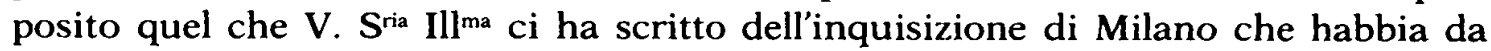


canoniques et politiques, le concile a voulu être un espace de miséricorde, mais cet espace est clos dans le temps comme dans l'espace. Les acclamations finales prononcées le 4 décembre 1563 par le cardinal de Lorraine se concluent significativement par : "Anathème à tous les hérétiques» ${ }^{108}$. Tant que le concile n'avait pas terminé ses travaux, l'erreur était encore tolérable. Mais comme il était de la dignité d'un concile de pouvoir réconcilier sans difficulté un hérétique, il y va maintenant de la dignité de ses décrets de ne plus tolérer les dissidents. La place est libre pour la Contre-Réforme, parce que la Réforme catholique est enclenchée.

Alain TALLON

essere secundum ius commune et non habbia da pregiudicare a gli ordinarii nè da depender dalla inquisition di Spagna ma dalla $S^{\text {ta }}$ di N. $S^{\text {re }}$, et con questo sappiamo che questi prelati s'allegreranno assai. Et pur che $S$. $B^{\text {ne }}$ faccia che non vi sieno ministri Spagnuoli et ci sieno le conditione tutte sopradette, non sarà chi non laudi ch'ella metta la detta inquisitione per li tempi che correno, tanto più essendo $\mathrm{V}$. Sria Illma pastor di quelle città ", J. Susta éd., op. cit., 4, p. 229, lettre du 9 septembre 1563. ${ }^{108}$ CT IX, p. 1109. 